\title{
BMJ Open Sport and scholastic factors in relation to smoking and smoking initiation in older adolescents: a prospective cohort study in Bosnia and Herzegovina
}

\author{
Damir Sekulic, ${ }^{1,2}$ Nedim Sisic, ${ }^{1,3}$ Admir Terzic, ${ }^{4,5}$ Indira Jasarevic, ${ }^{5}$ \\ Ljerka Ostojic, ${ }^{1,6,7}$ Haris Pojskic, ${ }^{8,9}$ Natasa Zenic ${ }^{1}$
}

To cite: Sekulic D, Sisic N, Terzic A, et al. Sport and scholastic factors in relation to smoking and smoking initiation in older adolescents: a prospective cohort study in Bosnia and Herzegovina. BMJ Open 2017;7:e014066. doi:10.1136/bmjopen-2016014066

- Prepublication history and additional material is available. To view please visit the journal (http://dx.doi.org/ 10.1136/bmjopen-2016014066).

Received 29 August 2016 Revised 30 January 2017 Accepted 2 February 2017

CrossMark

For numbered affiliations see end of article.

Correspondence to Professor Natasa Zenic; natasazenic@yahoo.com

\section{ABSTRACT}

Objective: Sport and scholastic factors are known to be associated with cigarette smoking in adolescence, but little is known about the causality of this association. The aim of this study was to prospectively explore the relationships of different sport and scholastic factors with smoking prevalence initiation in older adolescents from Bosnia and Herzegovina.

Methods: In this 2-year prospective cohort study, there were 872 adolescent participants (16 years at baseline; $46 \%$ females). The study consisted of baseline tests at the beginning of the third year (September 2013) and follow-up at the end of the fourth year of high school (late May to early June 2015). The independent variables were scholastic and sport-related factors. The dependent variables were (1) smoking at baseline, (2) smoking at follow-up and (3) smoking initiation over the course of the study. Logistic regressions controlling for age, gender and socioeconomic status were applied to define the relationships between independent and dependent variables.

Results: School absence at the baseline study was a significant predictor of smoking initiation during the course of the study (OR 1.4, 95\% Cl 1.1 to 1.8). Those who reported quitting sports at baseline showed an increased risk of smoking at the end of the study (OR $1.4,95 \% \mathrm{Cl} 1.1$ to 2.0 ) and of smoking initiation (OR $1.8,95 \% \mathrm{Cl} 1.3$ to 2.0 ). Adolescents who reported lower competitive achievements in sport were at a higher risk of (1) smoking at baseline (OR 1.5, 95\% $\mathrm{Cl} 1.1$ to 2.1), (2) smoking at follow-up (OR 1.5, 95\% $\mathrm{Cl} 1.1$ to 2.1 ) and (3) smoking initiation (OR 1.6, 95\% $\mathrm{Cl} 1.1$ to 2.6).

Conclusions: In developing accurate antismoking public health policies for older adolescents, the most vulnerable groups should be targeted. The results showed that most participants initiated smoking before 16 years of age. Therefore, further investigations should evaluate the predictors of smoking in younger ages.

\section{INTRODUCTION}

Cigarette smoking is an important modifiable determinant of health, and preventing

\section{Strengths and limitations of this study}

- The study lacks data on peer smoking and parental smoking, both of which can be associated with sport participation and educational achievement.

- Studied sport factors consisted of questions on formal sport participation, while some other important determinants of involvement in sport (non-formal physical exercising in fitness centres, self-exercising, etc) were not evaluated.

- The majority of participants started smoking before 16 years of age, and therefore the generalisability of the results regarding the predictors of smoking initiation is limited solely to adolescents who initiated smoking in late adolescence (16-18 years of age)

- This is one of the first studies to prospectively investigate the predictors of smoking in southeastern Europe.

- The high retention rate $(87 \%$ of the adolescents studied at baseline and follow-up) and low rate of missing data are important strengths of the study.

smoking initiation among adolescents eliminates the numerous health risks they would face as adult smokers. ${ }^{1}{ }^{2}$ With more than $20 \%$ of adolescents who smoke cigarettes daily, Bosnia and Herzegovina is among the five European countries with the highest prevalence of smoking among adolescents, together with Austria, Croatia, Belgium and Hungary (all about 20\% daily smokers). ${ }^{3} 4$ This high prevalence is mostly explained by the low prices of tobacco products, social acceptance of smoking in public and the lack of effective public health campaigns against smoking. ${ }^{5}$ Consequently, in the last couple of years, several cross-sectional investigations have explored the problem and found different sociodemographic, economic, community-specific, sport-related and 
scholastic factors to be associated with adolescent smoking in the country. ${ }^{6} 7$

Scholastic achievement (educational achievement) is one of the factors known to be associated with smoking in adolescence, with poor performance in school regularly observed in adolescents who smoke. ${ }^{5} 8-10$ However, the causality remains unknown. One possible explanation implies that smoking is the cause of poor performance in school because of the physiological mechanisms and the negative effects of smoking on cognitive function and learning capacities. ${ }^{11-13}$ Meanwhile, some authors are of the opinion that smoking should be observed as an effect, and not the cause, of educational failure. ${ }^{714}$ For example, children who fail academically are frequently in out-of-school situations where they are directly and/or indirectly exposed to individuals who smoke and are therefore at higher risk of smoking themselves. ${ }^{5}{ }^{6}$ Indeed, social influences are known to be important with respect to a wide range of health behaviours, including smoking, and such peer influence on smoking is also logical. ${ }^{15} 16$ However, it is also possible that other factors, such as parental conflict and/or poor familiar control, result in educational failure and smoking. Additionally, 'the theory of problem behaviour' (ie, that the problem behaviours such as failure in school and smoking often appear in tandem because some people have a psychosocial tendency for unconventionality) has been used to explain the association between educational failure and smoking in adolescence. ${ }^{17}$ Regardless of the background, the crosssectional design of the studies did not allow for the interpretation of the cause-effect relationship between educational achievement in high school and smoking status. $^{5} 718$

Participation in sport is often considered as a potentially effective way of reducing the tendency of adolescents to smoke cigarettes. ${ }^{19-22}$ Indeed, when comparing groups of adolescent athletes versus non-athletes, there is a lower prevalence of smoking in those involved in sports. ${ }^{23-25}$ However, when sport participation was analysed more specifically, there were some conflicting findings with the association between sports and cigarette smoking. ${ }^{26-28}$ For example, in a recent study, authors found that adolescents who had stopped participating in a sport were at high risk of misusing substances, while lower competitive achievement in sports was found to be associated with a higher likelihood of cigarette smoking. ${ }^{3} 527$ Again, owing to the cross-sectional study design, the causality is not clear. Indeed, smoking could impair physical capacity, thus leading to poor sport performance (a low result) and consequent withdrawal from sport. On the other hand, it is also possible that adolescents first stopped participating in sports and then started to smoke. ${ }^{27} 28$

This investigation aimed to prospectively explore the potential relationships between scholastic and sport factors at the beginning of the third year of high school, and smoking and smoking initiation in the following
2 years (from 16 to 18 years of age on average) in adolescents from Bosnia and Herzegovina. Understanding the relationships studied here may help inform all responsible parties about the specific risks and benefits related to the studied covariates of smoking. Although there are other potential predictors of smoking, in this study we were specifically focused on scholastic and sport factors, as both groups of factors are regularly and independently monitored throughout the school system and a better understanding of the associations could help develop cost-effective and targeted preventive interventions.

\section{METHODS}

\section{Procedures and participants}

In this study, we aimed to prospectively investigate adolescents over their last 2 years of high school. At baseline, the examinees were 16 years old on average and were in their third year of high school. A multistage cluster sampling method was used to select the participants. First, we randomly selected one-third of the high schools in the territory of Zenica-Doboj Canton and Tuzla Canton, mostly because of their sociocultural environments as described below.

Bosnia and Herzegovina is a multiethnic country, home to three constitutive ethnicities (Bosniaks, Serbs and Croats). Devastating wars that occurred in the early 1990s resulted in massive emigrations of minority ethnic groups (specifically for different parts of the country), and overall material devastation. ${ }^{29}$ For the two Cantons studied, prewar ethnic figures did not change drastically. Therefore, these two Cantons should be observed as two typical regions in Bosnia and Herzegovina.

School size varied by just $10-15 \%$, and therefore the schools were not stratified by size. In the second stage of sampling, half of all third year classes were selected at random from the selected schools, resulting in a sample size of 44 classes and a cohort of 1213 participants. After obtaining the necessary ethics approvals (see later text), study personnel explained the full procedure and study aims to potential participants and at least one parent/ guardian in a regular school meeting. Consent was obtained from at least one parent, and none of the parents refused to let their child participate in the study.

Two surveys were conducted, one (baseline) at the beginning of the third year of high school (September 2013), and the second (follow-up) at the end of high school (late May to early June 2015). Surveys were administered during school hours in groups of at least 15 examinees. Examinees were assured that their participation was voluntary and that they could leave any of the questions and/or the entire questionnaire blank. The study participants remained anonymous (no personal data were collected), but the participants were asked to use self-selected confidential codes for identification purposes in the repeated test. They were asked to use the last three digits of their email password as their code 
for identification (ie, these codes were easy to remember between testing waves while being simultaneously confidential). After completing the surveys, each participant placed the questionnaire in an envelope and then in a closed box. The next day, an investigator who was not present during the survey administration opened the boxes. The study fulfilled all ethical guidelines. After obtaining ethical approvals, the study was officially authorised by the Ministries of Education in Zenica-Doboj Canton and Tuzla Canton, the two areas of Bosnia and Herzegovina where the research was taking place. The study design and sampling is presented in figure 1.

Of the 1213 eligible students, 1059 (87\%) had complete data both at baseline and in the follow-up study. Of the latter, 872 who identified as Bosnians were included in the study ( $72 \%$ of the total eligible). The analysis of attrition bias showed no significant differences in initial smoking status between adolescents who dropped out and those who remained in the study $\left(\chi^{2}\right.$ $2.11, \mathrm{p}>0.05)$, but there were significantly more men than women who dropped out $\left(\chi^{2} 8.00, \mathrm{p}<0.01\right.$; see online supplementary table).

\section{Variables}

To extend current knowledge and allow meaningful comparison with previous cross-sectional reports from countries belonging to former Yugoslavia, such as Bosnia and Herzegovina, the variables were collected using the Questionnaire of Substance Use, which was previously reported to be a reliable and valid measuring tool in similar samples of participants. ${ }^{6727}$ In this study, we collected data on age (in years), gender, self-reported socioeconomic status (below average, average, above average), ethnicity (Bosniak, Serbian, Croatian, other), sport factors, scholastic factors and consumption of cigarettes.

Sports factors consisted of questions about the participants' (1) involvement in sports (answers included: never been involved, quit, currently involved); (2) highest competitive achievement in sports (never competed/did not participate in sports, local ranked competitions, national and international ranked competitions) and (3) time of involvement in sports (never involved, $<1,2-5,5+$ years). Scholastic variables represented participants' academic achievement over the past semester (end of the second year of high school): (1) grade point average; (2) behavioural grade (both on a five-point scale ranging from excellent to poor) and (3) school absences (almost never, rarely, from time to time, often). Cigarette smoking was assessed on a four-point scale with the following responses: 'no, I don't smoke', 'from time to time, but not daily', ' $<10$ cigarettes daily', and 'more than 10 cigarettes daily'. Participants were later
Figure 1 Sampling procedure, participants and non-responders (ie, absent from school on testing day, inconsistency in identification codes).

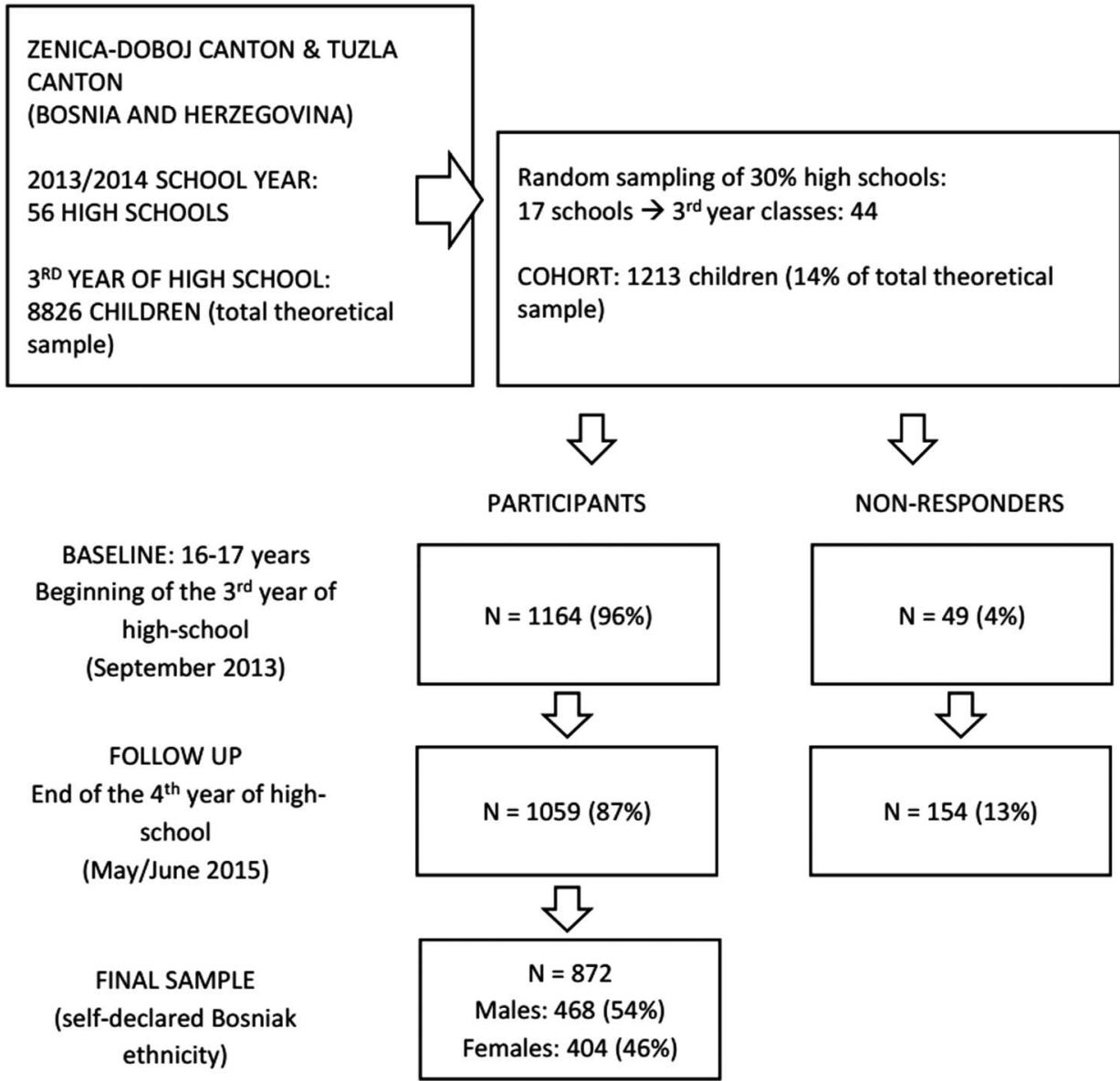


classified as non-smokers (those who responded with 'no, I don't smoke') or smokers (the remaining three answers). Information on smoking initiation during the course of the study was obtained from each participant. Specifically, if the participant reported not smoking at baseline and responded differently when tested at follow-up, the initiation of smoking was indicated.

\section{Statistics}

For all variables, descriptive statistics (counts and percentages or means and SDs) were calculated. Depending on the characteristic of the variable, the differences between smokers and non-smokers were established by the Mann-Whitney test (for ordinal variables), or $\chi^{2}$ test (for categorical variables). Binary logistic regression was used to estimate the OR and the corresponding 95\% CI of the following: (1) smoking status at baseline, (2) smoking status at the end of the study and (3) smoking initiation occurring during the course of the study by scholastic and sport covariates. The logistic analyses were additionally adjusted for gender, age and socioeconomic status.

\section{RESULTS}

Table 1 presents the distribution of independent variables according to smoking status at baseline and follow-up. Overall, 28\% of adolescents were identified as smokers at the beginning of their third year of high school, and $36 \%$ were smokers at the end of high school 20 months later. An increase in smoking prevalence over the observed period was particularly evident in women (from $27 \%$ to $38 \%$, and $30 \%$ to $34.5 \%$ for women and men, respectively). At baseline and at follow-up, nonsmokers achieved better grade point averages (Mann-Whitney Z values (MW) 6.03 and 6.36, $\mathrm{p}<0.01$ ) and better behavioural grades (MW 7.76 and 7.71, $\mathrm{p}<0.01$ ) and were less absent from school (MW 5.60 and 9.30, $\mathrm{p}<0.01$, for baseline and follow-up, respectively) than smokers. Non-smokers achieved higher sports results than smokers at baseline (MW 2.34, p<0.01).

Increased odds of smoking were observed in adolescents with a lower grade point average at baseline (baseline: OR 1.6, 95\% CI 1.4 to 1.9; follow-up: 1.7, 1.4 to 1.9), poorer behavioural grades (baseline: 2.6, 2.0 to 3.5; follow-up: 2.3, 1.7 to 2.9) and more frequent absences from school, with the highest chances of being smokers for those children who reported that they were often absent from school (baseline: 4.4, 2.0 to 9.4; follow-up: $4.5,2.1$ to 9.4 ). School absence at baseline was a significant predictor of smoking initiation over the course of the study as children who reported that they were absent from time to time having the highest chances of starting smoking during the course of study (2.6, 1.5 to 4.8). Involvement in sports (sport participation) was not associated with smoking status at baseline, but those who reported quitting sports showed an increased risk of smoking at the end of the study $(1.4,1.0$ to 1.9$)$ and a higher risk of smoking initiation during the study (1.7, 1.1 to 2.9). Adolescents who were engaged in sports for $<5$ years showed a higher prevalence of smoking at the end of the study ( $<1$ year: $2.7,1.6$ to 3.8 ; $2-5$ years: 2.4 , 1.6 to 3.6$)$, and an increased risk of smoking initiation during the course of the investigation $(<1$ year: $2.7,1.4$ to 5.2 ; $2-5$ years: $3.3,1.6$ to -6.2 ) than those who were never involved in sports. Finally, compared with peers who were never involved in sports, those who reported involvement in sports competitions but with lower competitive results were at a higher risk of the following: (1) smoking at baseline (1.5, 1.1 to 2.0), (2) smoking at the end of the study (1.5, 1.1 to 2.0) and (3) smoking initiation (1.6, 1.1 to 2.5 ; table 2 ).

\section{DISCUSSION}

This study aimed to prospectively investigate the potential relationships between scholastic and sport factors with smoking in older adolescents. The analyses revealed several important findings that should be highlighted. First, baseline scholastic factors were systematically associated with smoking, with poorer scholastic achievement in adolescents who reported smoking at baseline and follow-up. The absence from school at baseline was a predictor of smoking initiation in the following period. Quitting sports, poor competitive achievement and $<5$ years of participation in sports were shown to be specific risks for smoking and smoking initiation. Prior to discussing these findings, we will provide a brief overview of the established prevalence and trends in smoking. Smoking prevalence significantly increased from $28 \%$ to $36 \%$ during the course of the study. Consequently, $\sim 77 \%$ of adolescents who reported smoking at the end of high school (ie, 28/36) initiated smoking when they were younger than 16 years. Although participants selfreported their smoking status, which should be observed as a limitation of the study, the reported prevalence of smoking in this study is similar to previous reports of a $30-35 \%$ prevalence of adolescent smokers in Bosnia and Herzegovina and the wider territory of former Yugoslavia. ${ }^{327}{ }^{30}$ Consequently, the self-reported data on smoking obtained here are plausible. This study is unique, as it is one of the first to prospectively investigate the factors associated with smoking in adolescents from south-eastern Europe. Therefore, the data on the relationships between scholastic and sport factors and smoking initiation are particularly interesting.

The associations between scholastic factors and smoking at study baseline (ie, when participants were 16 years old) and the associations between scholastic factors and smoking at follow-up (ie, end of high school, 18 years of age) are similar. In both waves, higher odds of smoking are observed in adolescents with lower scholastic achievement. Our findings are therefore in accordance with the results of previous cross-sectional studies performed with adolescents of a similar age, which repeatedly reported lower educational achievement 
Table 1 Baseline and follow-up characteristics with differences on a basis of smoking status (MW—Mann-Whitney $Z$ values; $\chi^{2}$ test)

\begin{tabular}{|c|c|c|c|c|c|c|}
\hline & \multicolumn{3}{|l|}{ Baseline } & \multicolumn{3}{|l|}{ Follow-up } \\
\hline & $\begin{array}{l}\text { Smokers } \\
\text { f (\%) }\end{array}$ & $\begin{array}{l}\text { Non-smokers } \\
\mathrm{f}(\%)\end{array}$ & $\begin{array}{l}\text { MW } \\
Z \text { ( } p \text { value) }\end{array}$ & $\begin{array}{l}\text { Smokers } \\
\text { F (\%) }\end{array}$ & $\begin{array}{l}\text { Non-smokers } \\
\text { F (\%) }\end{array}$ & $\begin{array}{l}\text { MW } \\
Z \text { ( } p \text { value) }\end{array}$ \\
\hline Experience in sport & & & $1.54(0.12)$ & & & $0.93(0.34)$ \\
\hline Never been involved & $180(28.8)$ & $56(22.6)$ & & $174(31.3)$ & $62(19.6)$ & \\
\hline Less than a year & $132(21.2)$ & 56 (22.6) & & $104(18.7)$ & $84(26.6)$ & \\
\hline $2-5$ years & $164(26.3)$ & $72(29)$ & & $136(24.5)$ & $100(31.6)$ & \\
\hline$>5$ years & $148(23.7)$ & $64(25.8)$ & & $142(25.5)$ & 70 (22.2) & \\
\hline Sport success/result & & & $2.34(0.02)$ & & & $0.96(0.33)$ \\
\hline Never competed & $344(55.1)$ & $114(46)$ & & $308(55.4)$ & $150(47.5)$ & \\
\hline Local rank & $230(36.9)$ & $116(46.8)$ & & $204(36.7)$ & $142(44.9)$ & \\
\hline National/international & $44(7.1)$ & $18(7.3)$ & & $40(7.2)$ & $22(7)$ & \\
\hline Grade point average & & & $6.03(0.01)$ & & & $6.36(0.01)$ \\
\hline Excellent & $262(42)$ & $66(26.6)$ & & $242(43.5)$ & $86(27.2)$ & \\
\hline Very good & 246 (39.4) & 96 (38.7) & & 222 (39.9) & $120(38)$ & \\
\hline Average & $106(17)$ & 76 (30.6) & & $86(15.5)$ & $96(30.4)$ & \\
\hline Under average & $6(1)$ & $4(1.6)$ & & $2(0.4)$ & $8(2.5)$ & \\
\hline Poor & $4(0.6)$ & $6(2.4)$ & & $4(0.7)$ & $6(1.9)$ & \\
\hline Behavioural grade & & & $7.76(0.01)$ & & & $7.71(0.01)$ \\
\hline Excellent & $538(86.2)$ & $180(72.6)$ & & $500(89.9)$ & $218(69)$ & \\
\hline Very good & $46(7.4)$ & $26(10.5)$ & & $24(4.3)$ & $48(15.2)$ & \\
\hline Average & $30(4.8)$ & $28(11.3)$ & & $24(4.3)$ & $34(10.8)$ & \\
\hline Under average & $6(1)$ & $8(3.2)$ & & $6(1.1)$ & $8(2.5)$ & \\
\hline Poor & $4(0.6)$ & $6(2.4)$ & & $2(0.4)$ & $8(2.5)$ & \\
\hline School absence & & & $5.60(0.01)$ & & & $9.30(0.01)$ \\
\hline Almost never & $244(39.1)$ & $52(21)$ & & $246(44.2)$ & $50(15.8)$ & \\
\hline Rarely & 244 (39.1) & $102(41.1)$ & & $206(37.1)$ & $140(44.3)$ & \\
\hline From time to time & 108 (17.3) & 78 (31.5) & & 90 (16.2) & $96(30.4)$ & \\
\hline Often & $28(4.5)$ & $16(6.5)$ & & $14(2.5)$ & $30(9.5)$ & \\
\hline & & & $\chi^{2}(p$ Value $)$ & & & $\chi^{2}$ ( $p$ Value $)$ \\
\hline Gender & & & $0.82(0.36)$ & & & $1.32(0.25)$ \\
\hline Male & $138(29.7)$ & $326(70.3)$ & & $160(34.5)$ & $304(65.5)$ & \\
\hline Female & $110(27.0)$ & $298(73.0)$ & & $156(38.2)$ & $252(61.8)$ & \\
\hline Sport participation & & & $0.46(0.80)$ & & & $3.79(0.15)$ \\
\hline Currently involved & $128(20.5)$ & $56(22.6)$ & & $118(21.2)$ & 66 (20.9) & \\
\hline Quit & 206 (33) & 80 (32.3) & & 170 (30.6) & $116(36.7)$ & \\
\hline Never been involved & $290(46.5)$ & $112(45.2)$ & & $268(48.2)$ & $134(42.4)$ & \\
\hline Socioeconomic status & & & $5.66(0.06)$ & & & $2.58(0.27)$ \\
\hline Under average & $10(1.6)$ & $4(1.6)$ & & $10(1.8)$ & $4(1.3)$ & \\
\hline Average & $574(92.0)$ & 238 (95.7) & & $512(92.1)$ & $300(95.0)$ & \\
\hline Below average & $40(6.4)$ & $6(2.4)$ & & $34(6.1)$ & $12(3.8)$ & \\
\hline
\end{tabular}

among children who smoke. ${ }^{7} 1827$ Although there is a general consensus on the negative associations between smoking and performance in school, the mechanisms that lead to these associations are still controversial. Some authors highlight the negative effects of smoking on cognitive capacities, and consequently poorer learning capabilities, as a result of cigarette smoking. ${ }^{18}$ This explanation is strongly supported by the evident physiological mechanisms (ie, alterations in brain structure as a result of smoking). ${ }^{11-13}$ The main criticism of this explanation arises from the relatively short period of smoking in adolescents. Therefore, significant deterioration in cognitive capacities (and the resulting low academic achievement in adolescents) is less probable. As a result, it is suggested that lower academic achievement in adolescent smokers may actually be the cause, and not the effect, of smoking. Indeed, children who fail at school are frequently in 'out-of-school situations' and therefore in unique sociocultural environments in which they are more likely to initiate smoking. ${ }^{36}$ This theory thus focuses on social influence. In this study, we showed a negative relationship between 'school absence' at baseline (ie, 16 years of age) and smoking initiation in the following 2-year period. Therefore, our results actually support the theory of social influence as a probable explanation of the cause-effect relationship between academic failure and smoking in this age group. Briefly, the general associations between 
Table 2 The ORs for smoking at baseline, smoking at follow-up and smoking initiation over the course of the study

\begin{tabular}{|c|c|c|c|c|c|c|}
\hline \multirow[b]{2}{*}{ Baseline characteristics } & \multicolumn{3}{|l|}{ Bivariate analyses } & \multicolumn{3}{|l|}{ Model 1 * } \\
\hline & Smoking at baseline & Smoking at follow-up & Smoking initiation & Smoking at baseline & Smoking at follow-up & Smoking initiation \\
\hline Grade point average (grade) $\dagger$ & $1.6(1.4$ to 1.9$)$ & $1.6(1.4$ to 1.9$)$ & $1.1(0.9$ to 1.4$)$ & $1.6(1.4$ to 1.9$)$ & $1.7(1.4$ to 1.9$)$ & $1.2(0.9$ to 1.4$)$ \\
\hline Behavioural grade (grade) $†$ & 2.5 (1.9 to 3.3$)$ & 2.1 (1.6 to 2.7$)$ & 0.9 (0.6 to 1.3$)$ & 2.6 (2.0 to 3.5$)$ & 2.3 (1.7 to 2.9$)$ & 0.9 (0.6 to 1.3$)$ \\
\hline \multicolumn{7}{|l|}{ School Absence } \\
\hline Almost never & REF & REF & REF & REF & REF & REF \\
\hline Rarely & $2.0(1.4$ to 2.8$)$ & $2.3(1.7$ to 3.2$)$ & $1.7(1.0$ to 2.8$)$ & $2.0(1.4$ to 2.7$)$ & 2.3 (1.7 to 3.2$)$ & 1.7 (1.1 to 2.8$)$ \\
\hline From time to time & $2.7(1.7$ to 4.2$)$ & $3.5(2.3$ to 5.4$)$ & 2.5 (1.4 to 4.6$)$ & 2.7 (1.7 to 4.2$)$ & $3.6(2.3$ to 5.5$)$ & $2.6(1.5$ to 4.8$)$ \\
\hline Often & 4.0 (1.9 to 8.6$)$ & 4.1 (2.0 to 8.6$)$ & $1.7(0.5$ to 5.0$)$ & 4.5 (2.1 to 95$)$ & $4.5(2.1$ to 9.4$)$ & $1.8(0.6$ to 5.5$)$ \\
\hline \multicolumn{7}{|l|}{ Sport participation } \\
\hline Never been involved & REF & REF & REF & REF & REF & REF \\
\hline Currently involved & $1.1(0.8$ to 1.7$)$ & $1.2(0.8$ to 1.6$)$ & $1.2(0.8$ to 1.8$)$ & $1.1(0.7$ to 1.7$)$ & $1.2(0.8$ to 1.8$)$ & $0.9(0.5$ to 1.8$)$ \\
\hline Quit & $1.0(0.7$ to 1.4$)$ & $1.4(1.0$ to 1.9$)$ & $1.7(1.1$ to 2.7$)$ & $1.0(0.7$ to 1.4$)$ & $1.4(1.0$ to 1.9$)$ & 1.7 (1.1 to 2.9$)$ \\
\hline \multicolumn{7}{|l|}{ Experience in sport } \\
\hline Never been involved & REF & REF & REF & REF & REF & REF \\
\hline Less than a year & $1.3(0.9$ to 2.1$)$ & $2.3(1.5$ to 3.4$)$ & 2.6 (1.4 to 4.9$)$ & $1.4(0.9$ to 2.1$)$ & 2.7 (1.6 to 3.8$)$ & 2.7 (1.4 to 5.2 ) \\
\hline $2-5$ years & $1.4(0.9$ to 2.1$)$ & $2.1(1.4$ to 3.0$)$ & $2.8(1.5$ to 5.2$)$ & $1.4(0.9$ to 2.1$)$ & $2.4(1.6$ to 3.6$)$ & 3.3 (1.7 to 6.2$)$ \\
\hline$>5$ years & $1.4(0.9$ to 2.1$)$ & $1.4(0.9$ to 2.0$)$ & 1.1 (0.6 to 2.3$)$ & $1.4(0.8$ to 2.2$)$ & $1.5(0.9$ to 2.5$)$ & $1.4(0.7$ to 2.9$)$ \\
\hline \multicolumn{7}{|l|}{ Sport success/result } \\
\hline Never competed & REF & REF & REF & REF & REF & REF \\
\hline Local rank & 1.5 (1.1 to 2.1$)$ & $1.4(1.1$ to 1.9$)$ & 1.5 (1.0 to 2.2$)$ & 1.5 (1.1 to 2.0$)$ & 1.5 (1.1 to 2.0$)$ & $1.6(1.1$ to 2.5$)$ \\
\hline National/international & $1.2(0.7$ to 2.2$)$ & $1.1(0.6$ to 1.9$)$ & 0.9 (0.4 to 2.4$)$ & $1.3(0.7$ to 2.2$)$ & $1.2(0.7$ to 2.1$)$ & $1.0(0.4$ to 2.4$)$ \\
\hline
\end{tabular}


scholastic variables and smoking are clear, demonstrating that children who smoke perform poorly in school. However, it must be stressed that more frequent absences from school at the beginning of the third year of high school is a clear predictor of smoking initiation in the following 2 years. Of course, one can argue that scholastic achievement was not entirely objectively evaluated because the data were self-reported. Although this should be considered an important limitation of the study, we believe that the strict anonymity of the testing decreased the possibility that the participants responded dishonestly.

Our study found a high risk for smoking initiation for those adolescents (1) who quit sport, (2) who reported low competitive success and (3) who had a relatively short period of involvement in sport. Generally, this is in accordance with very recent studies which have noted a higher prevalence of smoking in adolescents who quit sports and those who achieved poorer competitive results. ${ }^{728}$ Owing to the cross-sectional nature of studies, the cause-and-effect relationship between quitting sports and smoking had not been clearly identified. There is a possibility that smoking impairs physical capacities, and this could therefore result in poor sport performance and a lack of success, which would consequently result in withdrawal from sports. ${ }^{31}$ However, it is also possible that children first stop practising a sport and then start to smoke, as a result of the (negative) influence of their new sociocultural environment in which smoking is more prevalent. ${ }^{5}$ The results of our study support the latter explanation. Specifically, all three sport factors observed in this study were found to be significant predictors of smoking initiation in older adolescents. First, those who reported at study baseline that they had once practised sports and then quit were at a higher risk of starting to smoke during the course of the study (ie, between 16 and 18 years of age) than their peers who were never involved in sports. Additionally, a higher risk of initiating smoking was evident in adolescents who were involved in sports for $<5$ years and in those who practised sports but did not achieve significant competitive results. Most probably, the association of all three sport factors ((1) quitting sport, (2) short time of involvement and (3) low competitive result) with smoking initiation is generated by equal mechanism. Briefly, it is well known that better sport results are actually a direct or indirect consequence of a longer involvement in sport. ${ }^{32} 33$ At the same time, a lack of good sports results (ie, poor competitive achievement in sport) is one of the most important factors which results in withdrawing from a sport in adolescence. ${ }^{34}$ The adolescents aged 16-18 years who do not achieve competitive results regularly stop participating in sports at this particular age, mostly because they have become personally aware of their inferiority (ie, their lack of ability and/or skills). ${ }^{34}$ Meanwhile, it is known that individuals identify with particular groups of peers, and being a member of a specific social network or group influences individuals' values as well as their attitudes and the norms to which they are exposed. ${ }^{35}$ Therefore, it is likely that adolescents who quit sports started smoking as a way of adopting the norms of the 'non-sporting' society and of finding a place in a new social milieu. This study lacks qualitative data on the reasons for quitting sports and an objective evaluation of lower competitive achievement in sports. This is a clear limitation of the investigation, as we are not able to accurately explain the background of the relationship within the sport factors observed here.

This study evidenced specific associations between scholastic and sport factors with smoking initiation in older adolescents, but we may not ignore the potential confounding effects of some covariates that were not observed in this study, such as those concerned with the home environment (ie, familiar factors). For example, it could be expected that both quitting sports and poor academic performance (ie, significant predictors of smoking initiation in our participants) might be a result of some family-related issues such as lack of parental monitoring and high parental conflict. Consequently, the lack of information on these issues could be highlighted as a study limitation. However, we were of the opinion that eventual knowledge of these confounding effects, although scientifically interesting, may not add much to our understanding of how to intervene. This is because children who have problems in their home environment, such as being in conflict with their parents and/or experiencing a lack of parental control, could not be tracked (ie, information on that manner was not obtainable). Meanwhile, all variables included in this study were easily obtainable throughout the education system, which allows identification of those children who are at specific risk for smoking initiation in late adolescence.

The most important limitation comes from the fact that this study observed adolescents from 16 years of age, when many students had already started to smoke. Therefore, the generalisability of the findings is limited to older adolescents. Next, data on peer smoking and parental smoking were not collected. It is reasonable to expect that these two factors could be determinants of sport and educational factors, and consequently directly and/or indirectly influence the associations studied in this investigation. Also, we have evaluated 'formal' sport participation only, while some potentially important determinants of physical exercising (ie, self-exercising, fitness centres) were not observed. Finally, students were asked on scholastic achievement over the past semester, which is a relatively crude indicator of overall school success. Therefore, in future studies, more precise evaluation of physical activity and accurate depiction of changes in scholastic achievement (ie, positive or negative changes in scholastic success) are necessary.

In order to objectively overview the findings, some specific contextual information on the sociocultural environments is necessary. Bosnia and Herzegovina is a country 
which is traditionally oriented towards tobacco consumption since the country was part of the former Ottoman Empire, and tobacco farming has been an important part of the economy in some cantons for more than 300 years (eg, particularly in the Herzegovina-Neretva Canton, which is the Mediterranean part of the country). ${ }^{6}$ As a result, smoking is socially accepted in public, and cigarettes are relatively cheap. Next, although smoking is prohibited in schools, such regulations are really only imposed for closed high school buildings. It is probably even more important that smoking is not prohibited in places of social gatherings (eg, pubs, cafe bars and disco clubs). Finally, although smoking is formally allowed only for those over 18 years, there is no ID control for purchasing cigarettes, while cigarette vending machines are also common. Therefore, although the generalisability of the findings is somewhat limited (mostly for Bosnian and Herzegovinian adolescents aged 16-18 years), the authors are of the opinion that the generalisability is to some extent possible for surrounding countries as well. This is because in many of the countries of former Yugoslavia, smoking is a socially accepted behaviour, there are no strict regulations against smoking in public, and tobacco products are relatively cheap. ${ }^{28} 30$

The following conclusions can be made. With $28 \%$ of adolescents who started smoking before they were 16 and an additional $8 \%$ who started smoking between 16 and 18 years of age, the prevalence of smoking is high. As expected from previous investigations, the smoking prevalence was higher in adolescents who achieved poor grades in school. This study expands on previous knowledge by demonstrating that school absences at the age of 16 are a predictor of smoking initiation over the next 2 years (ie, by the end of high school). Additionally, adolescents who reported quitting sports, those who were involved in sports for a relatively short time (ie, up to 5 years), and those who achieved low competitive success by the age of 16 were found to be at risk of starting smoking by the end of high school (ie, 18 years of age). Therefore, to develop accurate and problem-oriented public health policies against smoking in older adolescents, public health authorities should cooperate with school and sport organisations to target the most vulnerable groups of adolescents established in this study. Although it was not among the primary aims of the study, this was the first investigation which indirectly showed that the majority of adolescents from Bosnia and Herzegovina started smoking cigarettes before 16 years of age. Therefore, further investigations should evaluate the predictors of smoking in younger ages.

\footnotetext{
Author affiliations

${ }^{1}$ Faculty of Kinesiology, University of Split, Split, Croatia

${ }^{2}$ University Department of Health Care Studies, Split, Croatia

${ }^{3}$ University of Zenica, Zenica, Bosnia and Herzegovina

${ }^{4}$ High School Hasan Kikic, Gradacac, Bosnia and Herzegovina

${ }^{5}$ Faculty of Physical Education and Sport, University of Tuzla, Tuzla, Bosnia and Herzegovina
}

${ }^{6}$ University of Mostar, Mostar, Bosnia and Herzegovina

${ }^{7}$ Academy of Medical Sciences of Bosnia and Herzegovina, Sarajevo, Bosnia and Herzegovina

${ }^{8}$ Department for Health Sciences, Mid Sweden University, Östersund, Sweden ${ }^{9}$ Mid Sweden University, Swedish Winter Sports Research Centre, Östersund, Sweden

Acknowledgements Special thanks go to the Cantonal Ministries of Education which supported and approved the investigation. The authors are particularly grateful to all children who voluntarily participated in the study.

Contributors DS designed the study, performed the statistical analysis and discussed the data; NS, AT and IJ collected the data, overviewed previous research and drafted the manuscript; LO collected the data and discussed the public health issues of the investigation; HP overviewed the previous research and discussed the sport factors in relation to smoking; NZ discussed the data and participated in statistical analyses. All authors have read and approved the final version.

Funding This study and publication were partially financed by the University of Split, Faculty of Kinesiology, Split, Croatia.

Competing interests None declared.

\section{Patient consent Obtained.}

Ethics approval The Ethical Boards of University of Split, Faculty of Kinesiology, Split, Croatia and University of Mostar, School of Medicine, Mostar, Bosnia and Herzegovina approved the investigation. Additionally, the study was approved by the Cantonal Ministries of Education.

Provenance and peer review Not commissioned; externally peer reviewed.

Data sharing statement Data files are freely available here: https://www. dropbox.com/s/n7opixov3hrglj8/data.xlsx?dl=0.

Open Access This is an Open Access article distributed in accordance with the Creative Commons Attribution Non Commercial (CC BY-NC 4.0) license, which permits others to distribute, remix, adapt, build upon this work noncommercially, and license their derivative works on different terms, provided the original work is properly cited and the use is non-commercial. See: http:// creativecommons.org/licenses/by-nc/4.0/

\section{REFERENCES}

1. Lee KJ. Current smoking and secondhand smoke exposure and depression among Korean adolescents: analysis of a national cross-sectional survey. BMJ Open 2014;4:e003734.

2. Gendall P, Hoek J, Marsh L, et al. Youth tobacco access: trends and policy implications. BMJ Open 2014;4:e004631.

3. Sekulic D, Ostojic M, Vasilj M, et al. Gender-specific predictors of cigarette smoking in adolescents: an analysis of sport participation, parental factors and religiosity as protective/risk factors. J Subst Use 2014;19:89-94.

4. The 2011 ESPAD report; substance use among students in 36 European countries; http://www.can.se/contentassets/ 8d8cb78bbd28493b9030c65c598e3301/the_2011_espad_report_ full.pdf (accessed 20 July 2016).

5. Zenic N, Terzic A, Rodek J, et al. Gender-specific analyses of the prevalence and factors associated with substance use and misuse among Bosniak adolescents. Int J Environ Res Public Health 2015;12:6626-40

6. Sekulic D, Ostojic M, Ostojic Z, et al. Substance abuse prevalence and its relation to scholastic achievement and sport factors: an analysis among adolescents of the Herzegovina-Neretva Canton in Bosnia and Herzegovina. BMC Public Health 2012;12:274.

7. Zenic N, Ostojic L, Sisic N, et al. Examination of the community-specific prevalence of and factors associated with substance use and misuse among rural and urban adolescents: a cross-sectional analysis in Bosnia and Herzegovina. BMJ Open 2015;5:e009446.

8. Latvala A, Rose RJ, Pulkkinen L, et al. Drinking, smoking, and educational achievement: cross-lagged associations from adolescence to adulthood. Drug Alcohol Depend 2014;137:106-13.

9. Wang $\mathrm{M}$, Zhong JM, Fang $\mathrm{L}$, et al. Prevalence and associated factors of smoking in middle and high school students: a school-based cross-sectional study in Zhejiang Province, China. BMJ Open 2016;6:e010379. 
10. Pennanen $M$, Vartiainen $E$, Haukkala $A$. The role of family factors and school achievement in the progression of adolescents to regular smoking. Health Educ Res 2012;27:57-68.

11. Starr JM, Deary IJ, Fox HC, et al. Smoking and cognitive change from age 11 to 66 years: a confirmatory investigation. Addict Behav 2007;32:63-8.

12. Whalley LJ, Fox HC, Deary IJ, et al. Childhood IQ, smoking, and cognitive change from age 11 to 64 years. Addict Behav 2005;30: 77-88.

13. Anstey KJ, von Sanden C, Salim A, et al. Smoking as a risk factor for dementia and cognitive decline: a meta-analysis of prospective studies. Am J Epidemiol 2007;166:367-78.

14. Bachman JG, O'Malley PM, Schulenberg JE, et al. The education-drug use connection: how successes and failures in school relate to adolescent smoking, drinking, drug use, and delinquency. Taylor \& Francis, 2012.

15. Simons-Morton BG, Farhat T. Recent findings on peer group influences on adolescent smoking. J Prim Prev 2010;31:191-208.

16. Filippidis FT, Agaku IT, Vardavas $\mathrm{Cl}$. The association between peer, parental influence and tobacco product features and earlier age of onset of regular smoking among adults in 27 European countries. Eur J Public Health 2015;25:814-8.

17. Jessor R, Donovan JE, Costa FM. Beyond adolescence: problem behaviour and young adult development. Cambridge University Press, 1994.

18. So WY. Association between cigarette consumption and academic achievement in Korean adolescents. Addict Res Theory 2014;22:424-30.

19. McGee CE, Trigwell J, Fairclough SJ, et al. Effect of a sport-for-health intervention (SmokeFree Sports) on smoking-related intentions and cognitions among 9-10 year old primary school children: a controlled trial. BMC Public Health 2016;16:445.

20. Veliz PT, Boyd CJ, McCabe SE. Competitive sport involvement and substance use among adolescents: a nationwide study. Subst Use Misuse 2015;50:156-65.

21. Mattila VM, Raisamo S, Pihlajamäki $\mathrm{H}$, et al. Sports activity and the use of cigarettes and snus among young males in Finland in 19992010. BMC Public Health 2012;12:230.

22. Guo H, Reeder Al, McGee R, et al. Adolescents' leisure activities, parental monitoring and cigarette smoking - a cross-sectional study. Subst Abuse Treat Prev Policy 2011;6:12.
23. Diehl K, Thiel A, Zipfel S, et al. How healthy is the behavior of young athletes? A systematic literature review and meta-analyses. J Sports Sci Med 2012;11:201-20.

24. Lisha NE, Sussman S. Relationship of high school and college sports participation with alcohol, tobacco, and illicit drug use: a review. Addict Behav 2010;35:399-407.

25. Adachi-Mejia AM, Carlos HA, Berke EM, et al. A comparison of individual versus community influences on youth smoking behaviours: a cross-sectional observational study. BMJ Open 2012;2:pii: e000767.

26. Grunbaum JA, Kann L, Kinchen SA, et al. Youth risk behavior surveillance-United States, 2001. MMWR Surveill Summ 2002;51:1-62.

27. Idrizovic K, Zenic N, Tahirajl E, et al. Cigarette smoking among 17-18 year old adolescents-prevalence and association with sociodemographic, familial, sport, and scholastic factors. Med $\mathrm{Pr}$ 2015;66:153-63.

28. Tahiraj E, Cubela M, Ostojic L, et al. Prevalence and factors associated with substance use and misuse among Kosovar adolescents; cross sectional study of scholastic, familial-, and sports-related factors of influence. Int J Environ Res Public Health 2016;13:pii: E502.

29. Tuathail GO, O'Loughlin J. After ethnic cleansing: return outcomes in Bosnia-Herzegovina a decade beyond war. Ann Assoc Am Geogr 2009;99:1045-53

30. Modric T, Zenic N, Sekulic D. Substance use and misuse among 17- to 18-year-old Croatian adolescents: correlation with scholastic variables and sport factors. Subst Use Misuse 2011;46:1328-34.

31. Sekulic D, Tocilj J. Pulmonary function in military divers: smoking habits and physical fitness training influence. Mil Med 2006;171:1071-5.

32. Sekulic D, Bjelanovic L, Pehar M, et al. Substance use and misuse and potential doping behaviour in rugby union players. Res Sports Med 2014;22:226-39.

33. Kondric M, Sekulic D, Petroczi A, et al. Is there a danger for myopia in anti-doping education? Comparative analysis of substance use and misuse in Olympic racket sports calls for a broader approach. Subst Abuse Treat Prev Policy 2011;6:27.

34. Lee M. Coaching children in sport: principles and practice. Taylor \& Francis, 2002.

35. Moore MJ, Werch CEC. Sport and physical activity participation and substance use among adolescents. J Adolesc Health 2005;36:486-93. 